\title{
Patients' primary activities prior to critical illness: how well do clinicians know them and how likely are patients to return to them?
}

\author{
Alexi T. Gosset ${ }^{1,2}$, Michael C. Sklar ${ }^{3 *}$, Aaron M. Delman ${ }^{4}$ and Michael E. Detsky ${ }^{2,3,5}$
}

Admission to the intensive care unit (ICU) can make patients feel anonymous and depersonalized [1]. Knowledge of a patient's primary activity can mitigate the risk of depersonalization by providing insight into a patient's values, preferences, and overall function. A patient's primary activity is defined by how they report spending their free time. This information can be used to engage in shared decisionmaking, ensuring patients receive care that is goalconcordant based on the feasibility of recovering from their critical illness [2]. Therefore, we conducted a prospective observational study to determine if ICU physicians and nurses could identify their patients' primary activities. Other objectives included determining if patients were able to return to these activities and the probability of patients surviving based on their primary activity.

From October 2013 to May 2014 [3], enrolled patients (or their surrogates) were asked to identify their primary activity prior to hospitalization (Table 1). Attending physicians and nurses on admission days 3-6 were asked to identify this activity. Patients were followed to 6 months after enrollment to assess if they had survived and returned to their activities.

We found that clinicians had low rates of reporting knowledge of their patients' primary activities at
$13 \%(38 / 303)$ and $12 \%(35 / 300)$ for nurses and physicians, respectively. Patients' primary activities were reported correctly for 7\% (20/303) and 5\% (15/300) of patients by nurses and physicians, respectively (Table 1). Among patient reported activities, the most frequent were employment $(29 \%, 88 / 303)$ and household work (17\%, 53/303). Among survivors $64 \%(110 / 173)$ could perform their primary activity at 6 months, 26\% (45/173) could not. For 10\% (18/ 173) of survivors we were unable to confirm if they returned to their primary activity (Table 2).

We believe that knowing how patients spend their time prior to their illness can help in shared decisionmaking and ensure the delivery of goal-concordant care [4]. In our study, ICU clinicians rarely reported knowing their patient's primary activity and were correct in only half of those responses, suggesting that ICU clinicians lack an understanding of their patients' lives prior to critical illness. This is consistent with previous work that assessed physicians' knowledge of patients' broader values [5]. The systematic collection of information related to patients' values may mitigate the risk of depersonalization. Further work is needed to understand the potential impact of whether knowledge of patient activities leads to improved health outcomes and the delivery of goal-concordant care.

\footnotetext{
* Correspondence: michael.sklar@mail.utoronto.ca

${ }^{3}$ Interdepartmental Division of Critical Care Medicine, University of Toronto,

600 University Ave, Suite 18-232-1, Toronto, ON M5G 1X5, Canada

Full list of author information is available at the end of the article
} 
Table 1 Activity category and frequency, description, ability to return to activity, and survival

\begin{tabular}{|c|c|c|c|c|c|c|}
\hline Activity category & Description and examples & $\begin{array}{l}\text { Full return to } \\
\text { activity }(\%)^{\mathrm{a}}\end{array}$ & $\begin{array}{l}\text { Did not fully return to } \\
\text { activity }(\%)^{b}\end{array}$ & Deceased $(\%)^{c}$ & Unknown (\%) & Total \\
\hline Employment & $\begin{array}{l}\text { Work, vocation, or employment } \\
\text { status }\end{array}$ & $33(38)$ & $26(30)$ & $28(32)$ & $1(1)^{\mathrm{e}}$ & 88 \\
\hline Student & Involves school or academics & $2(67)$ & $1(33)$ & $0(0)$ & $0(0)$ & 3 \\
\hline Physical activity & $\begin{array}{l}\text { Physical exercise or strain } \\
\text { (i.e., weight lifting, walking) }\end{array}$ & $13(45)$ & $4(14)$ & $12(41)$ & $0(0)$ & 29 \\
\hline Household & $\begin{array}{l}\text { Chores requiring some amount } \\
\text { of activity (i.e., cleaning } \\
\text { house, shopping) }\end{array}$ & $17(32)$ & $10(19)$ & $24(45)$ & $2(4)$ & 53 \\
\hline Active & $\begin{array}{l}\text { Involves activity but not as main } \\
\text { focus (i.e., traveling, fishing) }\end{array}$ & $4(44)$ & $1(11)$ & $4(44)$ & $0(0)^{e}$ & 9 \\
\hline Social & $\begin{array}{l}\text { Engaging with other people } \\
\text { (i.e., family time, visiting } \\
\text { friends, therapy) }\end{array}$ & $14(45)$ & $2(6)$ & $13(42)$ & $2(6)$ & 31 \\
\hline Active sedentary & $\begin{array}{l}\text { No physical strain but requires } \\
\text { active engagement (i.e., arts } \\
\text { and crafts, reading) }\end{array}$ & $7(28)$ & $1(4)$ & $15(60)$ & $2(8)$ & 25 \\
\hline Passive sedentary & $\begin{array}{l}\text { No physical strain and no active } \\
\text { engagement (i.e., watching TV) }\end{array}$ & $20(50)$ & $0(0)$ & $17(43)$ & $3(8)$ & 40 \\
\hline Not reported & No activity listed & NA & NA & $17(68)$ & $8(32)$ & 25 \\
\hline Total & NA & $110(36)$ & $45(15)$ & $130(43)$ & $18(6)$ & 303 \\
\hline
\end{tabular}

${ }^{\mathrm{a}}$ Frequency and percentage of patients within each activity category that were alive and fully returned to their primary activity 6 months post-enrollment in the study. All percentages calculated by dividing the frequency by the activity type's total

${ }^{\mathrm{b}}$ Frequency and percentage of patients within each activity category that were alive but did not fully return to their primary activity 6 months post-enrollment in the study

'Frequency and percentage of patients within each activity category that were deceased 6 months post-enrollment in the study

${ }^{d}$ Frequency and percentage of patients within each activity category with unknown vital and/or return to pastime status 6 months post-enrollment in the study

e Percentages do not add to $100 \%$ due to decimal place rounding

Table 2 Physician and nurse accuracy in predicting patient primary activities

\begin{tabular}{|c|c|c|}
\hline & Physicians $(n=300 ; \%)^{a}$ & Nurses $(n=303 ; \%)^{a}$ \\
\hline Correct $^{\mathrm{b}}$ & $15(5)$ & $20(7)$ \\
\hline Incorrect $^{c}$ & $18(6)$ & $13(4)$ \\
\hline No patient response ${ }^{d}$ & $2(1)$ & $5(2)$ \\
\hline No clinician response $e^{e}$ & $265(88)$ & $265(87)$ \\
\hline
\end{tabular}

${ }^{\mathrm{a}}$ Total number of responses and percentage relative to total patient count

${ }^{b}$ Instances where clinician and patient primary activity responses agreed

${ }^{c} C l i n i c i a n$ and patient primary activity responses disagreed

${ }^{d}$ Patient provided no activity response but the clinician did

${ }^{\mathrm{e}}$ Clinician failed to provide an activity response

\section{Abbreviations}

ICU Intensive care unit

\section{Acknowledgements}

None.

Funding

None.

\section{Availability of data and materials}

The datasets used and/or analyzed during the current study are available from the corresponding author on reasonable request.
Authors' contributions

ATG, MCS, AMD, and MED came up with study design, implementation, data analysis, and manuscript preparation. All authors read and approved the final manuscript.

Ethics approval and consent to participate

The University of Pennsylvania institutional review board approved this study.

Consent for publication

Not applicable.

Competing interests

The authors declare that they have no competing interests. 


\section{Publisher's Note}

Springer Nature remains neutral with regard to jurisdictional claims in published maps and institutional affiliations.

\section{Author details}

${ }^{1}$ Harvard University, Boston, Massachusetts, USA. ${ }^{2}$ Department of Medicine, Sinai Health System, Toronto, Ontario, Canada. ${ }^{3}$ Interdepartmental Division of Critical Care Medicine, University of Toronto, 600 University Ave, Suite 18-232-1, Toronto, ON M5G 1X5, Canada. ${ }^{4}$ Department of Surgery, University of Cincinnati School of Medicine, Cincinnati, Ohio, USA. ${ }^{5}$ Palliative and Advanced IIIness Research (PAIR) Center, University of Pennsylvania Perelman School of Medicine, Philadelphia, Pennsylvania, USA.

Received: 31 October 2018 Accepted: 28 November 2018

Published online: 17 December 2018

\section{References}

1. Brown SM, Azoulay E, Benoit D, Butler TP, Folcarelli P, Geller G, et al. The practice of respect in the ICU. Am J Respir Crit Care Med. 2018;197:1389-95.

2. Laine C, Davidoff F. Patient-centered medicine. A professional evolution. JAMA. 1996;275:152-6.

3. Detsky ME, Harhay MO, Bayard DF, Delman AM, Buehler AE, Kent SA, et al. Discriminative accuracy of physician and nurse predictions for survival and functional outcomes 6 months after an ICU admission. JAMA. 2017;317:2187-95.

4. Turnbull AE, Hartog CS. Goal-concordant care in the ICU: a conceptual framework for future research. Intensive Care Med. 2017:43:1847-9.

5. Uy J, White DB, Mohan D, Arnold RM, Barnato AE. Physicians' decision-making roles for an acutely unstable critically and terminally ill patient. Crit Care Med. 2013;41:1511-7. 